\title{
Quality of Work Life among Public Health Nurses: A Survey Comparison between Thailand and Japan
}

\author{
Patcharee KOMJAKRAPHAN ${ }^{1, *}$, Kurumi TSURUTA ${ }^{2}$, \\ Tamayo HASAGAWA ${ }^{2}$, Toshihiko YANAGITA ${ }^{3}$, Amy HOMBU ${ }^{4}$, \\ Piyanuch JITANOON ${ }^{1}$ and Karnsunaphat BALTHIP ${ }^{1}$
}

\author{
${ }^{I}$ Division of Community Nurse Practitioner, Faculty of Nursing, Prince of Songkla University, \\ Songkhla 90112, Thailand \\ ${ }^{2}$ Department of Community Health and Psychiatric Nursing, School of Nursing, Faculty of Medicine, \\ University of Miyazaki, Kiyotake-choMiyazaki 8891692, Japan \\ ${ }^{3}$ Department of Adult Health and Gerontological Nursing, School of Nursing, Faculty of Medicine, \\ University of Miyazaki, Kiyotake-cho Miyazaki 8891692, Japan \\ ${ }^{4}$ Language Education Center, University of Miyazaki, Gakuen Kibanadai Nishi Miyazaki 8892192, Japan
}

('Corresponding author's email: patcharee.ko@psu.ac.th)

Received: 13 August 2017, Revised: 30 June 2018, Accepted: 20 July 2018

\begin{abstract}
Researchers from Thailand and Japan have initiated a collaborative project to compare the Quality of Work Life (QWL) among public health nurses. Thus, the QWL of registered nurses working in a community in Thailand was identified and compared with the Public Health Nurses (PHNs) in Japan. The purpose of which was to determine the similarities and differences between the two countries regarding their nurses' quality of work life. The 42-item of Brooks' survey of Quality of Nursing Work Life (QNWL) was translated and evaluated in Thailand and Japan. There were 102 Thai and 209 Japanese public health nurses completed the questionnaire.

Findings showed that the QNWL level of both Thai and Japanese PHNs were at moderate level. Thai nurses scored higher than Japanese nurses in overall scores. Thai reported significantly higher on work design dimensions $(\mathrm{t}=9.12, \mathrm{p}<0.05)$. For both groups, three out of four dimensions were ranked in the same pattern in which home life/work life was recorded as the lowest. This was followed by work design and work context. However, Thai scored lowest on work world dimension, while Japanese scored highest on that dimension. Findings also showed significant association between country and age groups $\left(\chi^{2}=20.01, \mathrm{p}=0.00\right.$, marital status $\left(\chi^{2}=6.50, \mathrm{p}=0.01\right)$, education $\left(\chi^{2}=70.05, \mathrm{p}=0.00\right)$, and dependent family members $(\chi 2=128.16, p=0.00)$. No significant association was noted between country and gender $\left(\chi^{2}=0.37, p=0.54\right)$, and between country and work experience $\left(\chi^{2}=2.88, p=0.23\right)$. The findings extended our understanding of the Public Health Nurse's quality of work life that contributes to nursing in different cultural contexts through a rare direct comparison of Public Health Nurses between Thailand and Japan.
\end{abstract}

Keywords: Public health nurse, quality of work life, Thai-Japanese, comparison study

\section{Introduction}

The nursing shortages and high nursing turnover have become global issues. Nursing shortage refers to an overarching imbalance of supply and demand attributed to demographics, qualifications, availability and willingness to do the work [1]. According to the WHO, the greatest shortage of nurses is in Asia [2]. A recent report of the International Council of Nurses (ICN) on Asia nursing workforce profiles revealed that four out of eleven countries including Japan and Thailand face a shortage of nurses over the next 1- 
http://wjst.wu.ac.th

year to 10-year period [3]. Nursing shortage in both countries is caused by the increase of the demand while there is a decrease in supply. The quality of work life (QWL) is considered as a supply side issue. QWL serves as a predictor of nurses' intention to leave, the turnover [4,5] and their retention and job satisfaction [6]. However, most of the literatures on nurses' QWL have been investigated among nurses working at hospitals. Information on the QWL of nurses working at community is limited. The Public Health Nurses or Community Health Nurses is one category of nurses who has engaged in a wide range of professional activities to serve the community. Despite their comparable roles and responsibility, little is known about the differences in QWL of PHNs in different cultural contexts. The importance of developing a global knowledge has been recognized in nursing because many healthcare issues cross international borders. Thus, the need for a global exchange of knowledge and evidence is greater than ever [7]. Many international nursing research studies have been conducted; however, there are no international studies that compare QWL of PHNs across countries. Therefore, the purpose of this study was to investigate and compare QWL among PHNs in Thailand and Japan. Each of the QWL was investigated with self-reported survey and the results by country were compared and discussed.

\section{Materials and methods}

This study used a descriptive design. In this study, "Public Health Nurse" was defined as a nurse who is responsible in primary health care setting, providing a range of services for people living in community. The subjects were taken from two cross-sectional data set. This data set was designed to capture the QWL of two segments of the PHNs in Thailand and Japan. Both surveys were based on a selfadministered questionnaire. One was exclusively concerned with all nurses working at primary health care setting in Songkla province, Thailand $(\mathrm{N}=102$, response rate $67.1 \%)$. The other concerned with full time employed PHNs in Miyazaki prefecture, Japan $(\mathrm{N}=209$, response rate $49.6 \%)$.

Data was collected using Brooks' survey of Quality of Nursing Work Life (QNWL) [8]. The QNWL survey consisted of 42 items related to four dimensions: (a) work life/home life, (b) work design, (c) work context and (d) work world. The instrument asked the respondent-nurses how much they agree or disagree with each item on a 6-point scale ranging from 1 'strongly disagree' to 6 'strongly agree'. Reliability in scale of this instrument was calculated using Cronbach's $\alpha$ is .89 and the test-retest reliability was reported using Pearson's $r=0.90(n=53)$ [8]. The score of QNWL survey ranged from 42 - 246. The QNWL was divided into low, moderate, and high according to the scores. This is the same for each subscale. In addition to the original English format, the questionnaire used was translated into Thai and Japanese using a translating device and was back translated in order to capture the essential meaning of each items. A panel of three bilingual experts in public health research and in health management reviewed the questionnaire and assured its validity. Two pilot studies in Thailand and Japan were conducted to ensure the clarity and appropriateness of the questionnaire. In Thailand, test test-retest reliability was reported using Pearson's $r=0.91(n=30)$. While in Japan, test test-retest was not performed.

Since the study was conducted in two different countries, local research action rules and ethical guidelines were followed. In Thailand, the ethical aspect of this study was approved by the Faculty of Nursing, Prince of Songkla University ethics committee with the ethical approval ID of 05211.05/ 2558. The survey was sent to nurses working at health promoting hospital in Songkhla province. A coded return envelope and a cover letter that explained the detail and objective of the research, and illustrated the steps taken to maintain confidentiality, were sent. The return of the completed questionnaire was accepted as an indication of the participants' consent to participate in this study. In Japan, the ethical aspect of this study was approved by the Research Ethics Committee of Faculty of Medicine, University of Miyazaki, which strictly adhered to the Ethical Guideline for Clinical study released from the Ministry of Health, Labour and Welfare (MHLW), Japan. It has the ethical approval ID of $2016-218$. 


\section{Statistical analysis}

Chi-square test for independent was used to examine the relationship between PHNs in each country including the categorical demographic variables. Also, independent t-test was used to determine the difference between the quality of work life among Thai and Japanese PHNs. P values less than 0.05 is considered significant for all tests.

\section{Results and discussion}

The 311 subjects who participated in this study were delineated as $32.8 \%$ Thai and $67.2 \%$ Japanese. They had an average age of 39.63 years $(\mathrm{SD}=9.53)$. The average length of the respondents' experience as a registered nurse was 16.09 years. The majority of the respondent was female $(95.2 \%, \mathrm{n}=$ $296)$, married $(68.8 \%, n=214)$, and held either a bachelor degree $(63.7 \%, n=198)$ or below bachelor degree $(31.5 \%, \mathrm{n}=98)$. More than half of the respondents had dependent family members $(51.1 \%, \mathrm{n}=$ 159).

Table 1 Demographic characteristic of respondents in the two study populations.

\begin{tabular}{|c|c|c|c|c|c|c|c|c|}
\hline \multirow[t]{2}{*}{ Socio-demographic characteristics } & \multicolumn{2}{|c|}{$\begin{array}{c}\text { Thai } \\
(\mathrm{N}=102)\end{array}$} & \multicolumn{2}{|c|}{$\begin{array}{l}\text { Japanese } \\
(\mathrm{N}=\mathbf{2 0 9})\end{array}$} & \multicolumn{2}{|c|}{$\begin{array}{c}\text { Total } \\
(\mathbf{N}=\mathbf{3 1 1})\end{array}$} & \multirow[t]{2}{*}{$\chi^{2}$} & \multirow[t]{2}{*}{$p$-value } \\
\hline & $\overline{\mathbf{x}}$ & SD & $\bar{x}$ & SD & $\overline{\mathbf{x}}$ & SD & & \\
\hline Age (years) & 40.77 & 7.85 & 39.09 & 10.23 & 39.63 & 9.53 & & \\
\hline Work experience & 17.17 & 8.63 & 15.54 & 10.22 & 16.09 & 9.73 & & \\
\hline Socio-demographic characteristics & $\%$ & (n) & $\%$ & (n) & $\%$ & (n) & & \\
\hline Age (group) & & & & & & & 20.01 & 0.00 \\
\hline $20-40$ years & 41.2 & $(42)$ & 59.3 & $(124)$ & 53.4 & $(166)$ & & \\
\hline $41-60$ years & 58.8 & $(60)$ & 40.7 & $(85)$ & 46.6 & $(145)$ & & \\
\hline Gender & & & & & & & 0.37 & 0.54 \\
\hline Male & 5.9 & $(6)$ & 4.3 & (9) & 4.8 & $(15)$ & & \\
\hline Female & 94.1 & (96) & 95.7 & $(200)$ & 95.2 & $(296)$ & & \\
\hline Marital status & & & & & & & 6.50 & 0.01 \\
\hline Single and other & 21.6 & $(22)$ & 35.9 & $(75)$ & 31.2 & (97) & & \\
\hline Married & 78.4 & $(80)$ & 64.1 & $(134)$ & 68.8 & $(214)$ & & \\
\hline Level of education & & & & & & & 70.05 & 0.00 \\
\hline Below bachelor degree & 0 & 0 & 46.9 & $(98)$ & 31.5 & (98) & & \\
\hline Bachelor degree & 92.2 & (94) & 49.8 & $(104)$ & 63.7 & $(198)$ & & \\
\hline Above bachelor degree & 7.8 & $(8)$ & 3.3 & (7) & 4.8 & $(15)$ & & \\
\hline Work experience* & & & & & & & 2.88 & 0.23 \\
\hline$<5$ years & 18 & (19) & 20.6 & $(43)$ & 20.5 & $(62)$ & & \\
\hline $5-10$ years & 10.8 & (11) & 16.3 & (34) & 15.0 & (45) & & \\
\hline$>10$ years & 70.6 & $(72)$ & 58.8 & $(123)$ & 64.5 & $(195)$ & & \\
\hline Dependent family members & & & & & & & $\begin{array}{r}128.1 \\
6\end{array}$ & 0.00 \\
\hline Yes & 97.1 & (99) & 28.7 & $(60)$ & 51.1 & $(159)$ & & \\
\hline No & 2.9 & (3) & 71.3 & $(149)$ & 48.9 & $(152)$ & & \\
\hline
\end{tabular}

Chi square analyses were performed to check for significant associations between categorical demographic variables and country (Thai versus Japanese). A significant association was found between country and age groups $(\chi 2=20.01, p=0.00$, marital status $(\chi 2=6.50, p=0.01)$, with significantly more Japanese being single and others (separated, divorced) (35.9\% versus $21.6 \%$ ), while Thai being married $(78.4 \%$ versus $64.1 \%)$. A significant association also was found between education and country $\left(\chi^{2}=\right.$ $70.05, \mathrm{p}=0.00)$. Japanese respondents held below bachelor degree with a percentage of $46.9 \%$ than their 
http://wjst.wu.ac.th

Thai counterpart. Likewise, a significant association was noted between dependent family members and country $\left(\chi_{2}=128.16, p=0.00\right)$. Thai had more married respondents $(78.4 \%$ of Thai) than their Japanese counterpart. One possible explanation for the finding may be that the family of married respondents was bigger compared to other groups. Therefore, dependent family member may co-exist with them. In addition, extended families in Thailand have been rising progressively during the period of $1980-2005$ [9]. However, no significant association was noted between country and gender $(\chi 2=0.37, \mathrm{p}=0.54)$, and between country and work experience $(\chi 2=2.88, \mathrm{p}=0.23)$ (Table 1).

Mean scores along with SDs and level of QNWL are presented in Table 2. The 42-item QNWL was divided into four dimensions: home life/work life, work design, work context, and work world. The response for all the questions is on a 6-point scale. Since the numbers of items vary in dimensions, average overall and dimensions scores were used in the analyses for comparison convenience. The QNWL scores of both Thai and Japanese public health nurses were normally distributed with no skewing. The results of the present study showed that quality of work life of both Thai and Japanese PHNs were reported at moderate level which different from another country such as Saudi Arabia and Mexico [10], where the respondent were not satisfied with their QWL. Thai scored higher than Japanese in overall scores (Table 2). Closer examination of the dimension showed that Thai reported significantly higher on work design dimensions $(\mathrm{t}=9.12, p<0.05)$. For both groups, three out of four dimensions were ranked in the same pattern in which home life/work life was recorded as the lowest. This was followed by work design, and work context. However, Thai scored lowest on work world dimension, while Japanese scored highest on that dimension.

Table 2 Average quality of nursing work life (QNWL) questionnaire overall and dimension scores of the Thai and Japanese groups.

\begin{tabular}{lccccccc}
\hline & \multicolumn{3}{c}{$\begin{array}{c}\text { Thai } \\
(\mathbf{n = 1 0 2})\end{array}$} & \multicolumn{3}{c}{$\begin{array}{c}\text { Japanese } \\
(\mathbf{n = 2 0 9 )}\end{array}$} & \multirow{2}{*}{$\begin{array}{c}\boldsymbol{p} \text { - } \\
\text { value }\end{array}$} \\
\cline { 2 - 7 } & Mean & SD & QNWL level & Mean & SD & QNWL level & \\
\hline Overall QNWL & 4.05 & 0.48 & moderate & 3.61 & 0.47 & moderate & 0.06 \\
Work life-home life & 3.86 & 0.65 & moderate & 3.30 & 0.74 & moderate & 0.20 \\
Work design & 3.93 & 0.46 & high & 3.32 & 0.58 & moderate & 0.02 \\
Work context & 4.24 & 0.57 & moderate & 3.80 & 0.64 & moderate & 0.06 \\
Work world & 3.82 & .60 & moderate & 3.85 & 0.56 & moderate & 0.46 \\
\hline
\end{tabular}

For a more detailed QNWL profile in Thai and Japanese PHNs, the first three out of five top items were identical for two groups while no one out of the five bottom items was found common to both groups. Both groups tended to be satisfied with their co-worker, job security, where a form of training take place in a normal working situation. The finding corroborated previous reports on Japanese nurses' job satisfaction, in that the nurses in the study were most satisfied with their relationships with peers, patients/families, and supervisors [11]. In general, Thai PHNs seemed to be unsatisfied with their salary and benefit. Additionally, arranging daycare for elderly parents, task irrelevant, and space reserved to socialize were major concerns for Japanese PHNs.

The finding of this study describes the differences between Thai and Japanese PHNs in QWL. Although QWL of both Thai and Japanese PHNs were reported at moderate level, Thai scored higher than Japanese in overall scores. It seems that the QWL is influenced by many factors. Thus, changes in any of these factors may affect the QWL. Previous study of QWL of PHNs and its related factors showed a significant relationship between QWL and their education level [12,13]. When marital status was considered, married nurses were found to have significantly higher mean scores of QWL than other peers 
http://wjst.wu.ac.th

$[14,15]$. One explanation is that the majority of married nurses may have been living with their families, which contributed significantly to their work satisfaction [14]. Therefore, the higher score of Thai PHNs in this study can be attributed to them being married and who held more bachelor degree than their Japanese counterpart.

The work life/ home life dimension is defined as the interface between the nurse's work and home life. The findings of the present study showed that this dimension ranks the lowest by PHNs in both countries. They were least satisfied with work-life home life balance such as arranging day care for elderly parents which is found on the bottom items of Japanese PHNs. Japan has had a long history of disaster such as earthquakes and tsunamis [16]. In Japan, PHNs play a major role in planning and implementing public health activities in communities before, during, and after a disaster [17]. Japanese PHNs carry out their responsibilities, which are not limited to acute-phase care, often under difficult conditions $[18,19]$. Thus, PHNs have varied responsibilities in the situations of constant flux that follow disasters. Therefore, Japanese PHNs who performed these duties also experienced tension as a result of role conflict between their family and work commitments [20]. In addition, in the qualitative study of Sato et al. [21], the findings showed that PHNs risked her own life for the sake of members of the community, while desperately wanting to ensure her own family's safety.

Work world dimension is defined as the effects of broad societal influences and changes on the practice of nursing. This is implied on the positive image and impact of nurses to the lives of others, their adequate salary, and job security. The work world dimension was ranked highest among all QWL dimension by the Japanese cohort in this study whereas this dimension was ranked lowest by their counterpart. This suggest that, although Thai PHNs is a civil service career which widely regarded as a desirable route to job security, and social status, there still evident universal complaint about the inadequacy of government salaries. Recently, Civil Service Act in Thailand was promulgated. Under this Act, a new position classification system was applied to replace the old one. In the new system, the ranks in the civil service has been eliminated and made work at government sector less attractive. Therefore, despite the fact that Thai PHNs hiring status is civil servants which considered as important because it means job security and good welfare benefits, the elimination of rank in civil service may reduce bargaining power for salary increases. In addition, many nurses are also hired for positions lower than their qualifications which may explain why the Thai PHNs cohort in this study ranked the work world dimension the lowest.

Thai reported significantly higher on work design dimension which described about composition of nursing work and the actual work that nurses perform. In this study, the major concerns for Japanese PHNs on work design dimension as found on the bottom items were task irrelevant and the lack of numbers of RNs in work setting. This finding is consistent with the result from the previous study on nursing work design in Japan which found that long working hours and shift work were the issues in nurse environment [22]. Inadequate staffing pattern contributes to heavy workload which is one of the main factors for poor quality of work life [23]. Prior studies have acknowledged many factors that have an impact on the nurses' QWL such as organization climate and performing non-nursing task [7-10].

The work context dimension includes the practice settings within which nurses' work and explores the impact of the work environment on both nurse and patient systems. This dimension was ranked the highest by PHNs in both countries. Thai PHNs were most satisfied with adequate supervision and recognition such as "upper-level management has respected for nursing" which found on one of the top five items. Adequate supervision and interaction with the supervisions are considered as a key factor for the quality of work life [24]. Opportunities for professional development and organizational support for continuing education program were found to be key factors for Japanese PHNs' satisfaction. This is evident on one of the top five items that stated "access to degree completion programs through my work setting". The Japan Nurse Association (JNA) released clinical ladders for midwifery practice competencies as a tool applied to the country as a whole in 2012. Also they are developing nursing education programs in tandem with the levels of clinical ladders. The JNA has begun its efforts to develop standardized clinical ladders applicable to any local settings and to promote a ladder-based clinical evaluation system. 
http://wjst.wu.ac.th

\section{Conclusions}

The levels of QWL of the PHNs in both countries were at moderate levels. Thai reported significantly higher on work design dimensions. For both groups, three out of four dimensions were ranked in the same pattern in which home life/work life was recorded as the lowest. This was followed by work design, and work context. However, Thai scored lowest on work world dimension, while Japanese scored highest on that dimension. The results of this study provide basic information in understanding the quality of work life among PHNs in Thailand and Japan. A number of limitations in this study have been identified. The factors other than the variables studied here may affect quality of work life of the PHNs. As the sample in this study was on voluntary basis, the finding may limit the generalization of the study. In addition, the current study used a cross-sectional survey design which limits the observation of change over time. Future comparative study regarding QWL between PHNs should identify the determinants of QWL in each country focusing on the differences in the working system and cultural context.

\section{Acknowledgements}

This study was supported by the RDO Collaborative Research grant CR15187 to the Research and Development Office at Prince of Songkla University, Thailand.

\section{References}

[1] MW Kathleen. Healthcare's human crisis: The American nursing shortage. Health Workforce Solution 2002; 3, 309-12.

[2] World Health Organization (WHO), Available at http://www.who.int/workforcealliance/knowledge/ resources/GHWAa universal truth report.pdf?ua=1, accessed July 2017.

[3] Asia Nursing Workforce Forum. Nursing workforce profile database summary 2016, Available at: http://www.icn.ch/images/stories/documents/pillars/sew/Datasheet_Nursing_Workforce_Profile_A WFF_2016, accessed July 2017.

[4] AM Mosadeghrad, E Ferlie and D Rosenberg . A study of relationship between job stress, quality of working life and turnover intention among hospital employees. Health Serv. Manag. Res. 2011; 24, 170-81.

[5] L O'Brien-Pallas and A Baumann. Quality of nursing work life issues: A unifying framework Canadian. J. Nurs. Admin 1992; 5, 2, 12-6.

[6] MParveen, KMaimani and NM Kassim. Quality of work life: The determinants of job satisfaction and job retention among RNs and OHPs. Int. J. Emerg. Ment. Health 2016; 18, 742-51.

[7] FE Irvine, D Lloyd, PR Jones, DM Allsup and C Kakehashi. Lost in translation undertaking transcultural qualitative research. Nurse Res. 2007; 14, 46-59.

[8] BA Brooks. 2001, Development of an Instrument to Measure Quality of Nurses' Work Life. Ph.D. Dissertation. University of Illinois at Chicago, Chicago, USA.

[9] National Statistical Office. Core Social Indicators of Thailand 2006. Statistical Forecast Units, Bangkok, Thailand, 2006.

[10] L Nancy, C González, PI Maria, C Hortensia, F Florabel, G Tranquilina and C Frida. Quality of work life in primary care of nursing professionals in public health clinics in Tampico, Mexico. $J$. Hos. Admin 2016; 5, 90-6.

[11] M Yamashita, M Takase, C Wakabayshi, K Kuroda and N Owatari. Work satisfaction of Japanese public health nurses: Assessing validity and reliability of a scale. Nurs. Health Sci. 2009; 11, $417-$ 21.

[12] M Tayebeh, M Farzaneh and AIsmail. Quality of working life of nurses and its related factors. Nurs. Midwifery Stud. 2014; 3, 2.

[13] I Lee and HH Wang. Perceived occupational stress and related factors in public health nurses. $J$. Nurs. Res. 2002; 10, 253-60.

[14] MM Sahar and ES Hanaa. Relation between quality of work life and nurses job satisfaction at Assiut University Hospitals. Al-Azhar Assiut Med. J. 2015; 13, 163-71. 
http://wjst.wu.ac.th

[15] N Al-Enezi, RI Chowdhury, MA Shah and M Al-Otabi. Job satisfaction of nurses with multicultural backgrounds: A questionnaire survey in Kuwait. Appl. Nurs. Res. 2009; 22, 94-100.

[16] A Ishigaki, H Higashi, T Sakamoto and S Shibahara. The Great East Japan Earthquake and devastating tsunami: And update and lessons from the past great earthquake in Japan since 1923. Tokohu J. Exp. Med 2013; 229, 287-99.

[17] R Doran, H Oshitani, T Kamigaki, S Mimura, M Sato, B Tamamura and T Nishina. Public Health Recovery after the Great East Japan Earthquake: Experiences in Selected Areas of Miyagi Prefecture. Center for Community Health, Tohoku University Graduate School of Medicine \& Sasakawa Peace Foundation. Sendai City, Japan, 2013.

[18] C Jakeway, G LaRosa, A Cary and \& S Schoenfisch. The role of public health nurses in emergency preparedness and response: A position paper of the Association of State and Territorial Directors of Nursing. Public Health Nurs. 2008; 25, 353-61.

[19] H Okuda. Support activities of suffering from the natural disaster by public health nurse. J. Natl. Inst. Public Health 2008; 57, 213-9.

[20] A Urabe and NA Miyasono. Study on the stress of nurses who work in disaster areas: The process of how nurses cope with stress. Bull. School Health Sci. 2007; 17, 25-32.

[21] M Sato, F Atogami, Y Nakamura, Y Kusaka and T Yoshizawa. Experiences of public health nurses in remote communities during the Great East Japan Earthquake. Health Emerg. Disast. Nurs. 2015; 1, $1-10$.

[22] S Tanaka, Y Maruyama, S Ooshima and H Ito. Working condition of nurses in Japan: Awareness of work-life balance among nursing personnel at a university hospital. J. Clin. Nurs. 2011; 2, 12-22.

[23] SA Vagharseyyedin, Z Vanaki and E Mohammadi. The nature nursing quality of work life: An integrative review of literature. West J. Nurs. Res. 2011; 33, 786-804.

[24] S Knox, JA Irving and J Gharrity. The nursing shortage-it's back! JONAS Healthc. Law Ethics Regul. 2001; 3, 114-22. 